\title{
Mudanças psicossociais no contexto familiar após a desospitalização do sujeito com transtornos mentais*
}

\author{
Psychosocial alterations in family context after desospitalization of the individual with \\ mental disorders
}

Aline Aparecida Costa'; ${ }^{1}$ Érika Renata Trevisan²

'Graduada em Terapia Ocupacional pela Universidade Federal do Triângulo Mineiro (UFTM) - Uberaba (MG), Brasil. alineaccosta@gmail.com

${ }^{2}$ Mestre em Enfermagem Psiquiátrica pela Universidade de São Paulo (USP) - São Paulo (SP), Brasil. Professora Assistente do Curso de Terapia Ocupacional da Universidade Federal do Triângulo Mineiro (UFTM) - Uberaba (MG), Brasil.

erikatouftm@hotmail.com
RESUMO A partir da reforma psiquiátrica, pretendeu-se conhecer o contexto familiar após a desospitalização do sujeito com transtornos mentais, e como a reabilitação psicossocial tem se articulado nesse processo. Foram entrevistadas cinco pessoas, familiares de sujeitos com transtornos mentais atendidos em um CAPS, e foi utilizada a metodologia qualitativa com análise temática. A coleta dos dados se deu através de entrevistas semiestruturadas. Os resultados apontaram limitações nas trocas sociais e o CAPS como única referência social e de tratamento. Nas trocas materiais, os sujeitos não possuem trabalho com valor social, e nas trocas afetivas, verificaram-se características da desospitalização sobrecarregando os familiares. Mesmo assim, esses se mostram favoráveis a esse processo. Contudo, existe a necessidade de construção e ampliação da rede de apoio social.

PALAVRAS CHAVE: Transtornos mentais; Relações familiares; Desospitalização.

\begin{abstract}
Based on the psychiatric reform, it was intended to verify the family context after a desospitalization of the person with mental disorders and the ways how the psychosocial rehabilitation has been articulated in this process. Five people were interviewed, family and individuals with mental alterations receiving treatment in CAPs. In data collect, it was used semistructured interviews. The results showed limitations in social interchanges and CAPS as the unique reference about social support. Regarding the material interchanges, the individuals don't develop any work with social value. In emotional interchanges, it became evident characteristics of desospitalization overburdening other family members. Still they are favorable to this process. However, there's a need to construct and enlarge the social support network.
\end{abstract}

KEYWORDS: Mental disorders; Family relations; Desospitalization.

\footnotetext{
* Resultado do Trabalho de Conclusão de Curso (TCC), realizado para o Curso de Terapia Ocupacional da Universidade Federal do Triângulo Mineiro (UFTM) - aprovado pelo Comitê de Ética da UFTM, de acordo com o parecer no 1558.
} 


\section{Introdução}

A institucionalização do sujeito com transtornos mentais nos hospitais gerais foi uma estratégia elaborada para retirar dos olhos da sociedade aqueles que não seguiam os padrôes sociais de comportamento. A época histórica da 'grande internação' se deu no século XVII, período em que essas instituiçóes possuíam funções sociais e não médicas (FRAYZE-PEREIRA, 1984).

A psiquiatria tornou-se a ciência responsável por lidar com os sujeitos com transtornos mentais. Phillipe Pinel propôs o Tratamento Moral, no final do século XVIII, buscando humanizar o tratamento psiquiátrico através da quebra de grilhóes e do trabalho laboral (SOUZA; MIRANDA, 2007).

Historicamente, os métodos de tratamentos utilizados nas instituiçôes psiquiátricas não produziram os resultados esperados para os sujeitos alvos, e a falta de humanidade e autonomia desencadeou o surgimento de novas propostas, como o movimento de desinstitucionalização (MÂNGIA; NICÁCIO, 2001).

$\mathrm{O}$ movimento da desinstitucionalização surge no cenário mundial como um projeto de transformação da função social da instituição psiquiátrica. A desinstitucionalização é um processo não apenas técnico, administrativo, jurídico, legislativo ou político; é, acima de tudo, um processo ético, de reconhecimento de uma prática que introduz novos sujeitos de direito e novos direitos para os sujeitos (AMARANTE, 1995). Desinstitucionalizar significa tratar o sujeito em sua existência e em relação as suas condições concretas de vida. Isso não significa administrar-lhe apenas fármacos ou psicoterapias, mas construir-lhe outras possibilidades (ROTELLI; DE LEONARDIS; MAURI, 2001).

Segundo Saraceno (2001), a desinstitucionalização difere da desospitalização quando considera que simplesmente esta saída do hospital não é suficiente para a participaçáo social. É necessário um processo de superação das condições de dependência institucional e da lógica da proteção e contençẫo que a instituição apresenta.

A reabilitação psicossocial e a desinstitucionalização fundamentam suas práticas na inclusão social e no retorno do sujeito com alteraçóes mentais para a família e para a comunidade. Visam a dar condições necessárias para que esse sujeito possa exercer suas potencialidades e capacidades com autonomia (TREVISAN, 2005).

Nesse sentido, Saraceno (2001) propóe a construção da cidadania, a restituição da contratualidade do sujeito nos aspectos da rede social, do habitat com a família e do trabalho com valor social. Esses são os eixos norteadores do processo de reabilitação psicossocial, que tem como finalidade ampliar os espaços de negociação e possibilitar as trocas sociais, materiais e afetivas.

$\mathrm{O}$ habitat refere-se às condiçóes materiais e afetivas de apropriação do local onde o sujeito mora com a família, bem como dos demais espaços sociais que frequenta. A rede de apoio social está ligada à possibilidade da construção de vínculos com a comunidade, com a família, com os serviços substitutivos, os quais, juntos, devem apoiar o sujeito com alteraçóes mentais em distintas situaçôes do cotidiano. Quanto ao trabalho com valor social, esse se relaciona com a validação social através da produção de mercadoria, geração de renda por meio dos distintos níveis de produção (SARACENO, 2001).

No Brasil, na década de 1970, sob influências da Declaração de Caracas, da desinstitucionalização italiana, da crise na Divisão Nacional de Saúde Mental, da organização do Movimento de Trabalhadores de Saúde Mental, da Reforma Sanitarista, de movimentos sociais e da luta pela redemocratização do País, impulsionou-se o movimento de reforma psiquiátrica (BALLARIN; CARVALHO, 2007).

A efetivação da reforma psiquiátrica depende de transformação em diferentes campos: teóricoassistencial, que implica mudanças nos conceitos e nas práticas referentes à saúde mental; técnicoassistencial, que busca a construção de novos serviços (Centros de Atenção Psicossocial, Oficinas Terapêuticas, Oficinas de Trabalho, Residências Terapêuticas) que possibilitem trocas e sociabilidade, bem como a inovação na gestão de serviços; jurídico-político, que busca a consolidação de leis que cumpram os direitos do sujeito com transtornos mentais; e, finalmente, no campo sociocultural, 
que intenta a transformação da visão social acerca da loucura (AMARANTE, 1995).

As mudanças ocorridas na política pública brasileira de atenção à saúde mental colocaram os sujeitos com transtornos mentais e seus familiares como protagonistas de um processo que busca inovar as formas de tratamento, "[...] visando a atender esta população e pautar-se no acolhimento, no estabelecimento de vínculos, na responsabilização, na ética e no cuidado" (MORENO, 2009, p. 567).

Em pesquisa realizada no final da década de 1990, percebeu-se que, no processo de desinstitucionalização ocorrido no País em decorrência do processo da reforma psiquiátrica, os familiares sofreram algumas alteraçóes em seu contexto, e apontou-se que o suporte da rede de apoio, bem como os princípios da reabilitação psicossocial não se apresentavam efetivos ou adequados. Dessa forma, algumas famílias - principalmente as pertencentes às classes sociais mais baixas - preferiam a institucionalização de seu familiar com alterações mentais (SADIGURSKY; TAVARES, 1998).

Assim, faz se necessária a reestruturação das crenças e das representaçóes da família acerca do tratamento. Após a desospitalizaçấo, a volta do sujeito para o lar e para a sociedade, de acordo com os preceitos da reforma e da inclusão social, trazem a indagação de como as famílias dos sujeitos com transtornos mentais interpretam essa nova situação (MACIEL et al, 2009).

Sendo assim, este estudo objetivou conhecer as possíveis mudanças ocorridas no contexto familiar após a desospitalização de seu membro com transtornos mentais e compreender como a reabilitação psicossocial tem se articulado nesse processo. Será utilizado o termo desospitalização, pois não há dados suficientes neste estudo para afirmar que tenha havido, de fato, a desinstitucionalização desses sujeitos com transtornos mentais.

\section{Procedimentos Metodológicos}

A pesquisa foi desenvolvida a partir de um estudo qualitativo que investigou as alteraçóes psicossociais ocorridas no contexto familiar após a desospitalização do sujeito com transtornos mentais. A aprovação pelo
Comitê de Ética da Universidade Federal do Triângulo Mineiro consta no protocolo ${ }^{\circ} 1558$.

Os dados foram coletados através de entrevistas semiestruturadas e gravados em mídia eletrônica. A transcrição das entrevistas foi feita na íntegra pela autora. A análise dos dados se deu através da construção de um conjunto de categorias descritivas. A formulação dessas categorias é o resultado de leituras sucessivas do material coletado, da ordenação dos relatos e da divisão do material em elementos componentes, que, posteriormente, foram reexaminados e formaram conceitos mais abrangentes (MINAYO, 2008).

Foram entrevistados oito familiares de usuários de um Centro de Atenção Psicossocial (CAPS) de um município de Minas Gerais. Porém, somente cinco deles responderam aos critérios de inclusão da pesquisa: ser familiar de um sujeito com transtornos mentais que possua histórico de hospitalização por aproximadamente seis meses, em qualquer instituição psiquiátrica, e assinar o Termo de Consentimento Livre e Esclarecido.

O roteiro da entrevista semiestruturada possuía perguntas relacionadas à identificação dos sujeitos da pesquisa (nome, idade, profissão, grau de parentesco com sujeito com alteraçôes mentais); histórico da alteração mental (como e quando se deram as primeiras crises, histórico familiar da doença, institucionalização e desospitalização, tempo de internação, condições de tratamento, envolvimento familiar, desinstitucionalização, encaminhamentos); ocupação/trabalho dos familiares, antes e depois da desospitalização, e rotina familiar (lazer, conflitos, cuidado, comunidade); serviços substitutivos (local, tempo que o sujeito com alteraçóes permanece em tratamento durante a semana, satisfaçáo dos familiares com o serviço, diferenças entre tratamento institucionalizado e na comunidade); crises; auxílio financeiro; e opinião dos familiares sobre a reforma psiquiátrica. Vale ressaltar que esses foram os eixos norteadores das perguntas, mas que houve abertura para o surgimento de outras indagaçóes.

As entrevistas foram realizadas nas residências dos sujeitos e para a identificação dos participantes foram utilizados nomes fictícios - os familiares receberam nomes de flores e os sujeitos com transtornos mentais receberam nomes de árvores, sendo eles: 
- Margarida, 74 anos, madrasta de Araçá, que é esquizofrênica desde a adolescência. Trabalhava como costureira de vestidos de noiva, mas agora só se dedica aos cuidados de Araçá e de sua própria saúde.

- Tulipa, 50 anos, casada, três filhos e dona de casa. Após o falecimento de sua mãe, cuida de seu irmão Pinheiro, esquizofrênico. Atuamente, ele é seu vizinho, vive um processo de reclusão e fica preso em um cômodo construído para isolá-lo da sociedade, saindo de casa somente para ir ao CAPS e nos momentos em que a irmã está na residência, auxiliandoo em suas atividades cotidianas.

- Jasmim, 67 anos, viúva e dona de casa. Mãe de Peroba, 43 anos, esquizofrênica desde a adolescência. Atualmente, Peroba permanece 15 dias em casa e 15 dias no hospital psiquiátrico. Essa estratégia vem sendo experimentada há cinco meses. Ela ficou dois anos internada.

- Cravo, 50 anos, casado, uma filha, porteiro. Cuida de seu irmão Carvalho, 55 anos, que tem esquizofrenia.

- Gerânio, 63 anos, jardineiro, solteiro. Mora sozinho, próximo à casa de seu irmáo Ipê, que tem esquizofrenia, cujo início das crises se deu quando ele tinha 19 anos. Ipê reside com mais duas irmãs, as quais auxiliam em seu cuidado. Gerânio é seu curador e frequenta as reunióes de famílias realizadas no CAPS.

\section{Resultados e Discussões}

Os temas mais abrangentes evidenciados na análise dos dados serão apresentados como: histórico da alteração mental, que aborda as primeiras crises e internaçóes dos sujeitos; reabilitação psicossocial, com enfoque nas trocas afetivas, sociais e materiais; e as redes de apoio social.

\section{Histórico da Alteração Mental}

Para se compreender a história do transtorno mental e sua influência no contexto familiar, faz se necessário compreender, inicialmente, como ocorreram as primeiras crises que a institucionalização.

Nas crises psiquiátricas, as principais reclamações apontadas pelos familiares são: agressividade, isolamento social, tentativas de autodestruição, falta de cooperação e de higiene. Tais comportamentos geram nos familiares distintos sentimentos, como raiva, culpa e medo, "[...] contribuindo para o sentimento de impotência frente à realidade inesperada" (SOARES; MUNARI, 2008, p. 358).

Os entrevistados relataram como foram as primeiras crises e internaçôes:

A primeira internação foi quando ela começou
a sentir assim, não queria dormir. Começou
falar que, no grupo, tinha uns menino jogan-
do areia no olho dela. Num tinha nada... As
professoras adoravam ela. Ela começou a não
querer estudar mais, começou a reclamar ar-
ranhão nos olhos, passou a náo querer dormir,
salivando demais. Não queria ir no banheiro.
(Jasmim).

Quando ele teve no hospital, lá em São Paulo, que ia visitar ele, lá na rua escutava o gemido dele no hospital. Aí, eu cheguei lá e ele tava só de cueca, lá, deitado no chão, amarrado. (Gerânio).

Saraceno (2001) afirma que a história da psiquiatria tem sido, também, a história das atitudes da psiquiatria, com relação à família do paciente: no velho manicômio, a família era o cúmplice designado para a internação do paciente identificado. A família era grata ao hospital por se ver aliviada do problema e a instituição se autorreproduzia, também, por essa gratidão. Entretanto, no caso dos sujeitos entrevistados nesta pesquisa, evidenciou-se que a maioria não considerava a internação como a melhor forma de cuidar do seu familiar. 
Eu acho que a pessoa que interna e fica um mês trancado deixa muita marca na pessoa. Agora, pra você ver, uma pessoa que fica doente, se ela tiver condição de passar daquela crise junto com os familiares, é bem melhor, né? (Cravo).

Após a desospitalização, percebe-se que o sujeito com transtornos mentais leva para seu cotidiano os sentimentos de injustiça, amargura e alienação, assim como as características massificadoras e normatizadoras das instituiçôes totais, mantendo sua conduta ainda nos parâmetros da condição de hospitalização à qual estava submetido. Segundo Goffman (1961), a internação em hospital para doentes mentais traz ao internado uma descaracterização de si e uma mortificação do eu, através de processos relativamente padronizados nessas instituições.

Ela custa a dar conta de tomar banho, quer ficar só dormindo. O probrema é esse. Depende d'ela querer ir, porque ela é muito medrosa. E o CAPS é muito longe. Ela fica mais é aqui dentro. Às vezes, ela vai no portão. Num sai na rua porque tem medo de cachorro. (Jasmim).

Machado, Manco e Santos (2005) afirmam que as pessoas que ficaram por anos institucionalizadas passam a conviver com um forte sentimento de insegurança quanto ao mundo extra-hospitalar, que, muitas vezes, lhe é passado como perigoso, hostil e preconceituoso.

A barreira entre a instituição e o mundo externo é o primeiro facilitador de mutilação do eu e das subjetividades; as perdas no convívio social podem não ser mais recuperadas; há a ausência de bens e a ausência de objetos pessoais que tem íntima ligação com o eu, perdendo seu conjunto de identidade. A instituição normalmente lhe fornece o que é necessário, de forma massificada, e o identifica com números para uma melhor organização. Além das relaçóes interpessoais impostas com as quais o internado tem que conviver no hospital, às vezes, ele ainda é obrigado a tomar a medicação e se alimentar mesmo contra a sua vontade. As pessoas que vivem em uma instituição por muitos anos são usualmente caracterizadas como dependentes, institucionalizadas e cronificadas. Para Goffman (1961), essa condição social de exclusão é mais importante e determinante no seu comportamento do que a própria doença mental.

Dessa forma, é possível perceber que um período elevado de internação transforma os sujeitos, ocasionando dificuldades relacionais ao seu contexto social, familiar e afetivo, visto que a maioria dos entrevistados não sabe lidar com as características geradas pelo tempo de internação.

\section{Reabilitação Psicossocial}

A reabilitação psicossocial é compreendida pelas ações que visam a modificar os níveis de relação de domínio, abrindo novos meios para se estabelecer relaçóes entre comunidade, serviços, profissionais, familiares e sujeitos. Ainda preconiza o desempenho do sujeito com transtornos mentais nas diversas esferas que compóem o seu cotidiano, favorecendo as trocas afetivas, materiais e sociais embasadas pela contratualidade com a rede de apoio que circunda esse sujeito na comunidade (SARACENO, 2001).

As trocas afetivas compreendem toda a afetividade, o cuidado, os sentimentos e as relaçóes entre o sujeito e seus familiares. As trocas materiais estão relacionadas ao trabalho dos familiares e dos sujeitos com transtornos mentais, à aposentadoria, a tudo o que se refere às finanças. Quanto às trocas sociais, trazem questôes relacionadas à sociedade e a seus valores, à relação da família com a sociedade e às consequências do isolamento social pela hospitalização.

\section{Trocas Afetivas}

Na pesquisa, ficou evidente a existência de trocas afetivas entre os sujeitos e seus familiares. Porém, essas trocas acontecem de diferentes formas, de acordo com as singularidades dos atores envolvidos nessa relação.

Foi um amor assim, cristão, que eu tive pelos dois (marido e enteada). Ela ficou sendo como se fosse uma filha. Então, tudo que eu passei, 
eu sei que é uma cruz, uma cruz muita pesada. Eu sei que tudo é para a glória de Deus. (Margarida).

Tratando-se das mudanças psicossociais ocorridas nesse contexto, fica claro que os familiares se sentem sobrecarregados nos casos de dependência afetiva. A falta de iniciativa apresentada pelo sujeito com transtornos mentais no auxílio das tarefas cotidianas aumenta a sobrecarga.

Bandeira e Barroso (2005) relatam que as limitaçóes no relacionamento do sujeito com seus familiares, e, em específico, a falta de reciprocidade da pessoa com transtornos mentais, é um aspecto negativo, que dificulta as relações saudáveis no dia a dia.

Tudo é eu: médico, higiene... Eu não dou banho nele, ele toma banho sozinho. Mas esquizofrênico não gosta de tomar banho. Ai, tem que ficar em cima dele: 'Já tomou banho?'. Ai, entro no banheiro: 'Deixa eu ver se você tá tomando banho direito! Faz assim, esfrega ai, me ajuda!'. (Cravo).

As trocas afetivas e emocionais vivenciadas pelos familiares no cotidiano, ao presenciarem o sofrimento do sujeito com transtornos mentais, são afetadas diretamente. Aparecem dificuldades pela falta de orientação sobre como agir nas distintas situações, por exemplo, durante as crises. Isso demonstra a necessidade desses familiares serem alvos de tratamento em saúde mental (PEGARARO; CALDANA, 2006).

Eu já tenho psiquiatra pra mim ir. A gente vai ficando atacado, né? Se a gente num toma um calmante. O doutor passou pra mim, pra poder dormir... (Gerânio).

\section{Trocas materiais}

Saraceno (2001) aponta a necessidade do trabalho com valor social, possibilitando a contratualidade com habitat e sociedade, e, também, possibilitando a reconstrução da cidadania e o respeito aos direitos humanos.
A família é um espaço social que promove a interação e o cuidado de seus membros quando uma enfermidade acomete algum de seus integrantes. Essa vivência pode ocasionar conflitos e dúvidas para os familiares envolvidos, e, muitas vezes, provocar 'instabilidade permanente na vida cotidiana' (CHIAGAVATTI et al, 2009, p. 133).

Assim sendo, os familiares sentem necessidade não só de dar apoio físico e emocional, mas também de suportar o impacto da estigmatização sofrida pelo sujeito com transtornos mentais. Esses encargos não se remetem apenas a afeto, emoção e estresse, mas afetam também o lado econômico (MACIEL et al, 2009).

Tem pessoas também que é agressiva e a família não tem condição financeira de fazer um cômodo, de ta ali, junto, num é verdade? A gente sabe que pros familiar não é fácil, porque você mexe com um doente mental sem isolar ele. Tá sujeito a machucar qualquer um, né? (Tulipa).

É, eu vinha, largava até o serviço, e ia satisfeito. Pra ele, eu busco o remédio, vou satisfeito. Pede guaraná, pede outra coisa. eu vou lá e compro. Satisfeito com ele. Se o dinheiro dele acaba, eu importo de dar do meu dinheiro, não. Eu não vou levar nada disso pro túmulo, tem que ajudar quem precisa, né? (Gerânio).

Maciel et al (2009) pontuam que o cuidar dos sujeitos com transtornos mentais demanda tempo e pode ocasionar restriçóes econômicas e sociais, visto que, em muitos casos, eles não exercem trabalho com valor social. No entanto, mesmo não tendo um trabalho remunerado, a maioria recebe aposentadoria ou auxílio-doença, não sobrecarregando as finanças da família e, em alguns casos, auxiliando diretamente no sustento desta.

É importante ressaltar que foi verificado, nas entrevistas, que não houve alteraçóes no papel ocupacional da maioria dos familiares participantes da pesquisa após a desospitalização, exceto no caso da Margarida, que passou a administração da oficina de costura de vestidos de noiva para sua filha, podendo, assim, dedicar-se aos cuidados de Araçá e de sua própria saúde. 


\section{Trocas sociais}

Gonçalves e Senna (2001, p. 51) apontam que a desinstitucionalização não espera mudar o local de exclusão, transferindo-o para a casa ou para os serviços, mas, busca a contratualidade com a sociedade, tornando o sujeito com transtornos mentais um cidadáo de direitos. Ainda, "[...] respeitar sua singularidade e subjetividade" e tornar esse sujeito protagonista de sua vida e de seu tratamento.

Foram apontadas limitaçóes nas relaçóes sociais dos sujeitos por parte da maioria dos familiares, reproduzindo, assim, os processos estigmatizantes que (re) afirmam a exclusão desses sujeitos.

A família busca a normalização dos sintomas, esperando do sujeito um comportamento semelhante ao preconizado pela sociedade. Rosa (2008) aponta que a família compartilha dos valores da sociedade. Dessa forma, ela sabe da estigmatizaçáo sofrida por seu familiar e adota essa conduta como mecanismo de defesa, porém, torna-se um agente estigmatizador.

Rosa (2008, p. 251) ainda classifica esse comportamento como superproteçáo, podendo '[...] ser compreendido como um desdobramento do sentimento de culpa', e este limita as relaçóes sociais dos familiares e dos sujeitos com alterações mentais.

A gente só não deixa ele sair na rua porque a gente tem medo. Por ter ficado doente durante muitos anos, ele perdeu muito a noção de atravessar uma rua, né? Então, ele sai ou é de carro ou é com a gente. Quando vai no barbeiro cortar o cabelo, ele vai andando, mas a gente junto. Então, agora, sozinho assim, a gente num acha que ele tá apto ainda. (Tulipa).

Além disso, o receio de o sujeito ter uma nova crise limita a sua participação social. Então, os familiares preferem ficar em casa e não relatam se incomodar com isso, visto que esse comportamento já faz parte de sua rotina.

Se eu for viajar sozinho e largar minha fitha com ele, eu não posso. Então, na verdade, muda, mas não muda, porque eu já acostumei. Tudo a gente acostuma. (Cravo).

Ela já teve o cartão de ônibus e nunca usou. Eu queria que tirasse, pra vermos se ela passeava de ônibus, ia a algum lugar. Mas ela não quer! (Jasmim).

\section{Redes de apoio social}

O CAPS é apontado como a única rede de apoio ofertada para os sujeitos e suas famílias. Tal fato limita a reinserção social e a concretização das propostas da reabilitação psicossocial. Bandeira e Barroso (2005) afirmam que não foram construídos os recursos comunitários necessários e adequados para atender às necessidades do sujeito com transtornos mentais e de seus familiares nas áreas de atendimento clínico, social e ocupacional.

O Ministério da Saúde define que o objetivo do CAPS é atender a população inserida em sua área de abrangência, através de acompanhamento clínico e reinserção social dos sujeitos por meio do trabalho com valor social, lazer, cumprimento dos direitos de cidadáo, fortalecimento e favorecimento dos laços com os familiares e na comunidade, tendo sido criado para substituir as internaçōes psiquiátricas (BRASIL, 2004).

Se não fosse o CAPS, tava enrolado. O CAPS tem um médico de cabeça, tem tratamento quase noite e dia. Na época que ele internava no sanatório era aquela judiação. Já vinha pra cá dando problema, tomando aquela mãozada de remédio, né? Agora, quando surgiu o CAPS, foi uma maravilha! (Gerânio).

Agora ele faz caminhada, faz alguma atividade manual, está aprendendo as coisas (no CAPS). Foi muito bom pra ele! Ele tá associando com as pessoas novamente lá fora, porque ficava muito em casa, só com a gente, só no meio da família. Lá ele tá fazendo amigo, conversa, né? (Tulipa). 
Outro aspecto relevante no processo de reforma psiquiátrica diz respeito à participação de usuários e familiares na organização e na discussão política em instâncias oficiais, visando à transformação do sistema de saúde mental e à construção de uma nova forma de lidar com as alteraçóes mentais dos sujeitos. Dessa forma, o usuário desse novo modelo deixaria de ser um objeto de intervenção para tornar-se agente de mudanças para a construção de uma nova realidade, edificando o sentido de cidadania. E o movimento passaria a circular em todas as instâncias, inclusive nas culturais e familiares (BRASIL, 2004).

Além disso, a participação ativa dos familiares nos serviços de saúde mental, como CAPS, é apontado por Bandeira e Barroso (2005) como necessária e pertinente, visto que pode favorecer a adesão e maximizar a satisfação dos sujeitos com o tratamento.

E sempre que tinha reuniáo da familia, eu ia. Hoje, num tem mais, parou. Até fazer parte da reunião era bom pra mim também. (Gerânio).

O CAPS foca seu tratamento no acolhimento e no vínculo, construindo projetos de inserção de seus usuários na comunidade, fundamentando-se na cidadania e na singularidade de cada sujeito com alteraçóes mentais. Dessa forma, reduz a estigmatização e promove qualidade de vida, sendo a família fundamental nesse processo (CHIAVAGATTI et al, 2009).

Assim, torna-se nítida a importância da família quando ela atua em parceria com os profissionais dos serviços de saúde mental, reduzindo a referência de atitudes negativas por parte dos sujeitos alvos de tratamento. Os últimos trabalhos referentes à saúde mental não estão voltados somente para o sujeito com alteraçôes mentais, mas incluem a sociedade em que estão inseridos, englobando também a família (BANDEIRA; BARROSO, 2005).

Alguns estudos mostraram que os familiares têm sofrido alteraçóes em seu contexto devido à reforma psiquiátrica não estar proporcionando adequado suporte à rede de apoio. Dessa forma, algumas famílias demonstravam sua preferência pela institucionalização (GONÇALVES; SENNA, 2001). Porém, esta pesquisa apontou que a maioria dos entrevistados apresenta um posicionamento favorável quanto à reinserção do sujeito na família.

Ele, medicado certinho, vai vivendo normal: come, dorme, conversa. Tem hora que conversa meio sem nexo, mas conversa, conhece as pessoas. Para mim, ele, não estando internado, tomando medicamento, na minha casa é melhor! (Cravo).

Tem que ser o atendimento que precisa mesmo. Ficar internado só quando precisar mesmo. Eu jamais quero ver ela internada. (Margarida).

\section{Considerações Finais}

Muitos avanços foram percebidos desde o início do movimento da reforma psiquiátrica brasileira nas formas de cuidar e assistir a população com transtornos psíquicos, entretanto, ainda há demandas a serem sanadas.

Este estudo trouxe contribuiçóes importantes ao destacar que, para os familiares, a saída da instituição e o convívio familiar são fatores positivos. Apesar das dificuldades cotidianas, eles avaliam favoravelmente tais medidas. Ficou claro também que não houve mudanças significativas nos aspectos psicossociais desses familiares, além, principalmente, do auxílio nos cuidados pessoais e cotidianos.

Entretanto, este estudo demonstrou que há necessidade de fortalecimento e ampliação da rede de suporte social que responda às necessidades das famílias e dos usuários dos serviços de saúde mental, sendo o CAPS a única referência social e de tratamento dessas pessoas. Assim, percebem-se restriçóes no estabelecimento da contratualidade desses sujeitos com a comunidade, dificultando a ampliação e a efetivação das trocas afetivas e materiais, bem como a inclusão social. 


\section{Referências}

AMARANTE P. Loucos pela vida: a trajetória da reforma psiquiátrica no Brasil. 2.ed. Rio de Janeiro: Ed. FIOCRUZ, 1995. 136p.

BALLARIN, M. L. G. S.; CARVALHO, F. B. Considerações acerca da reabilitação psicossocial: aspectos históricos, perspectivas e experiências. In: CAVALCANTI, A.; GALVÃO, C. Terapia Ocupacional: fundamentação e prática. Rio de Janeiro: Guanabara Koogam, 2007. p. 162-170.

BANDEIRA, M.; BARROSO, S. M. Sobrecarga das famílias de pacientes psiquiátricos. Jornal Brasileiro de Psiquiatria, Rio de Janeiro, v. 54, n. 1, p. 34-46, 2005.

BRASIL. Ministério da Saúde. Saúde mental no SUS: os centros de atenção psicossocial. Brasília: Ministério da Saúde, 2004. 86p.

CHIAVAGATTI, F. G. et al. A inserção da família nos centros de atenção psicossocial sob a ótica de seus atores sociais. Texto: Contexto Enfermagem, Florianópolis, v.18, n. 1, p. 131-139, jan./ mar. 2009.

FRAYZE-PEREIRA, J. O que é Loucura? 10. ed. São Paulo: Brasiliense, 2002. 107p.

GOFFMAN, N. E. Manicômios, Prisões e Conventos. 7. ed. São Paulo: Perspectiva, 1961. 320p.

GONÇALVES, A. M.; SENA, R. R. A Reforma Psiquiátrica no Brasil: contextualização e reflexos sobre o cuidado com o doente mental na família. Revista Latina Americana de Enfermagem, Ribeirão Preto, v. 9, n. 2, p. 48-55, mar. 2001

MACHADO, V; MANCO, A. R. X.; SANTOS, M. A. A recusa à desospitalização psiquiátrica: um estudo qualitativo. Cadernos de Saúde Pública, São Paulo, 2005, v. 21, n. 5, p. 1472-1479, 2005.

MACIEL, S. C. et al. Reforma psiquiátrica e inclusão social: um estudo com familiares de doentes mentais. Psicologia, ciência e profissão, Brasília, v. 29, n. 3, p. 436-447, set. 2009.

MÂNGIA, E. F.; NICÁCIO, F. Terapia Ocupacional em Saúde Mental: tendências principais e desafios contemporâneos. In: DE CARLO, M. M. R. P.; BARTALOTTI, C. C. Terapia Ocupacional no Brasil: fundamentos e perspectivas. São Paulo: Plexus, 2001. p. 63-80.
MINAYO, M. C. S. O desafio do conhecimento: pesquisa qualitativa em saúde. 11. ed. São Paulo: Hucitec, 2008. 269p.

MORENO, V. Familiares de portadores de transtorno mental: vivenciando o cuidado em um centro de atenção psicossocial. Revista da Escola de Enfermagem, São Paulo, v. 43, n. 3, p. 566-572, set. 2009.

PEGORARO, R. F.; CALDANA, R. H. L. Sofrimento psíquico em familiares de usuários de um Centro de Atenção Psicossocial (CAPS). Interface - Comunicação, Saúde, Educação, Botucatu, v. 12, n. 25, p. 295-307, abr./jun. 2008.

ROSA, L. C. S. A Relação da Família com o portador de transtorno mental. In: ROSA, L. C. S. Transtorno mental e o cuidado na família. São Paulo: Cortez, 2008. p. 235-242.

ROTELLI, F.; DE LEONARDIS, O; MAURI, D. Desinstitucionalização, uma outra via: a reforma psiquiátrica italiana no contexto da Europa ocidental e dos países Avançados. In: NICÁCIO, M. F. (org). Desinstitucionalização. 2. ed. São Paulo: Hucitec, 2001. p. 17-59.

SADIGURSKY, D.; TAVARES, J. L. Algumas considerações sobre o processo de desinstitucionalização. Revista Latino Americana de Enfermagem, Ribeirão Preto, v. 6, n. 2, p. 23-27, 1998.

SARACENO, B. Libertando identidades: da reabilitação psicossocial à cidadania possível. 2. ed. São Paulo: TeCorá, 2001. 176p.

SOUZA, G. B.; MIRANDA, C. A. C. O asilamento científico: A Institucionalização dos hospícios e o processo de exclusão social. Colóquio de História da Universidade Federal Rural de Pernambuco, 1., 2007, Pernambuco. Anais. Recife: UFPE, 2007. 9p.

SOARES, C;; MUNARI, D. Considerações acerca da sobrecarga em familiares de pessoas com transtornos mentais. Ciência, Cuidado e Saúde, Maringá, v. 6, n. 3, p. 357-362, jun. 2008.

TREVISAN, E. R. Programa Moradia Vila: ações realizadas na perspectiva de desinstitucionalização de moradores de um hospital psiquiátrico. 2005. 151 f. (Mestrado em Enfermagem Psiquiátrica) - Universidade de São Paulo, Escola de Enfermagem, São Paulo, 2005.

Recebido para publicação em Outubro/2011

Versão definitiva em Julho/2012

Suporte financeiro: não houve

conflito de interesse: inexistente 